\title{
BMJ Open Work-related mobility and experiences of gender-based violence among female sex workers in Iringa, Tanzania: a cross- sectional analysis of baseline data from Project Shikamana
}

\author{
Zoé Mistrale Hendrickson, ${ }^{1}$ Anna M Leddy, ${ }^{2,3}$ Noya Galai, ${ }^{4,5}$ Jessie K Mbwambo, ${ }^{6}$ \\ Samuel Likindikoki, ${ }^{6}$ Deanna L Kerrigan ${ }^{1,7}$
}

To cite: Hendrickson ZM, Leddy AM, Galai N, et al. Workrelated mobility and experiences of gender-based violence among female sex workers in Iringa, Tanzania: a cross-sectional analysis of baseline data from Project Shikamana. BMJ Open 2018;8:e022621. doi:10.1136/ bmjopen-2018-022621

\section{- Prepublication history for} this paper is available online. To view these files, please visit the journal online (http://dx.doi. org/10.1136/bmjopen-2018022621).

Received 26 February 2018

Revised 4 July 2018

Accepted 23 August 2018
Check for updates

(C) Author(s) (or their employer(s)) 2018. Re-use permitted under CC BY-NC. No commercial re-use. See rights and permissions. Published by BMJ.

For numbered affiliations see end of article.

Correspondence to Dr Zoé Mistrale Hendrickson; zhendri1@jhu.edu

\section{ABSTRACT}

Objectives To examine how work-related mobility among female sex workers (FSWs) is associated with gender-based violence (GBV) in Iringa, Tanzania.

Design Cross-sectional analyses were conducted on baseline data gathered between 0ctober 2015 and April 2016 from FSWs participating in Project Shikamana, a community empowerment-based combination HIV prevention intervention.

Setting Participants were recruited for the baseline study using venue-based time-location sampling in two communities in Iringa, Tanzania.

Participants FSWs were eligible for participation if they were 18 years or older and had exchanged sex for money within the past month. Four-hundred ninety-six FSWs participated in the baseline survey. Primary and secondary outcome measures Any recent experience of GBV was examined by recent work-related mobility among FSWs. Any recent experience of GBV was also disaggregated by severity for analyses. All bivariate and multivariate binary and multinomial logistic regressions adjusted for intraclass correlations among women recruited from the same venues.

Results Forty per cent of participants experienced recent physical or sexual violence, and $30 \%$ recently experienced severe physical or sexual violence. Thirtythree per cent of participants recently exchanged sex for money outside of their district or region, and $12 \%$ were both intraregionally and inter-regionally mobile for sex work. Intraregionally and inter-regionally mobile FSWs had 1.9 times greater odds of reporting recent GBV (adjusted OR: 1.89; 95\% Cl: 1.06 to $3.38 ; \mathrm{p}=0.031$ ) compared with non-mobile FSWs and a 2.5 times higher relative risk for recent experience of severe GBV relative to no recent GBV (relative risk ratio: $2.51 ; 95 \% \mathrm{Cl}: 1.33$ to $4.74 ; p=0.005$ ).

Conclusions Mobility for sex work may increase FSWs' exposure to GBV, particularly more severe GBV. The vulnerability of mobile FSWs to violence, particularly severe forms, demands inclusive services that are accessible to mobile FSWs.

\section{Strengths and limitations of this study}

- This study is strengthened by its involvement of female sex workers (FSWs) in all aspects of the study, including during formative work prior to the administration of the baseline survey, through a community advisory board, and by sharing findings from the baseline study with participants.

- Another strength of this study is the use of venue-based time-location sampling to recruit FSWs in Iringa, Tanzania, where the majority of FSWs are venue-based.

- Analyses are also strengthened by the disaggregation of recent experience of gender-based violence (GBV) among FSWs in Iringa, Tanzania, based on severity of violence rather than the sole use of a dichotomous measure of recent GBV.

- Generalisability of the findings is limited due to the cross-sectional design and the recruitment of FSWs from venues, since some FSWs may connect with their clients in other ways.

- There may be recall bias as a result of the use of self-reported measures of work-related mobility and GBV.

\section{BACKGROUND}

Female sex workers (FSWs) are at heightened risk for gender-based violence (GBV). ${ }^{12} \mathrm{GBV}$ is a human rights violation ${ }^{34}$ and is associated with several negative health outcomes. In addition to physical injury, ${ }^{5}$ GBV can increase FSWs' risk for HIV and other sexually transmitted infections directly (ie, through forced sex) and indirectly through inconsistent condom use and condom misuse. ${ }^{6-11}$ Modelling exercises with populations in Central Asia and East Africa have suggested that reductions in GBV would reduce $\mathrm{HIV}$ incidence among FSWs. ${ }^{10}{ }^{12} \mathrm{GBV}$ is also associated with poor mental health outcomes such as depression among FSWs. ${ }^{213-15}$ 
GBV against FSWs is shaped by the social and structural context in which sex work occurs. ${ }^{16} 17$ Structural factors including the criminalisation of sex work, inequitable gender norms and stigma and discrimination towards FSWs in countries around the world influence FSWs' GBV and HIV susceptibility. ${ }^{1216}$ These factors can significantly restrict FSWs' access to justice and health services like HIV testing, care and treatment. ${ }^{11819}$

Population mobility is an important contextual factor that impacts FSWs' daily lives. ${ }^{12}$ FSWs may travel or migrate to meet new clients, ${ }^{20}{ }^{21}$ or in response to stigma, discrimination or harassment from police. ${ }^{22}$ Temporary migration or mobility of FSWs is also related to work environments that increase their risk for GBV and HIV. ${ }^{23}$ Mobility has been associated with FSWs' venue type, ${ }^{24} 25$ which can affect the risk environment (eg, safety, access to support networks or violence) within which FSWs work. ${ }^{26}$ Mobile FSWs are more likely to report inconsistent condom use ${ }^{27} 28$ and may face greater challenges in negotiating condom use with clients or partners. ${ }^{22} 2527$ Mobility of FSWs is also associated with greater alcohol use, ${ }^{27}$ poor sexual health outcomes ${ }^{23}$ and reduced access to healthcare services. ${ }^{29}$

Recent studies in multiple settings have found a positive association between FSW mobility and experiences of GBV. ${ }^{23} 252730$ In India, mobile FSWs who had recently experienced violence had higher odds of having HIV and depressive symptoms than other FSWs. ${ }^{14}{ }^{23}$ Swain et al referred to this as 'double jeopardy' as a result of increased vulnerability at the intersections of these experiences (p. 8). ${ }^{31}$

Mobile FSWs are therefore an important population to study, since mobile populations may be more vulnerable due to unique exposures to HIV and other risks during mobility. ${ }^{20}{ }^{32}$ In a recent systematic review examining correlates of violence among sex workers, population mobility was positioned as a factor influencing FSWs' risk for GBV. ${ }^{2}$ While this review illuminated the potential role of mobility/migration in FSWs' risk of GBV, HIV and other poor health outcomes, no articles on mobility included in that systematic review were based on FSWs' experiences in sub-Saharan Africa-a setting where mobility remains an important aspect of FSWs' lives. ${ }^{20}$

Here, we built on findings from a recent systematic review by Deering et $a t^{2}$ to explore the possible linkages between population mobility and GBV among FSWs in Iringa, Tanzania. GBV is a concern for FSWs in Iringa, with a recent behavioural survey finding that $52 \%$ of FSWs reported experiencing physical violence in the past 6 months. ${ }^{33}$ As in other settings in sub-Saharan Africa, ${ }^{34}{ }^{35}$ sex work is criminalised in Tanzania, ${ }^{36}$ and stigma, discrimination and harassment of FSWs are common. ${ }^{37}$ Such stigma has been found to affect FSWs' access to and utilisation of services. ${ }^{38}$ Mobility in Iringa, similar to other settings in the region, is influenced by the Tanzanian-Zambian (Tan-Zam) highway that cuts through the geographical area. ${ }^{20} 39$ The movement of truck drivers ${ }^{39}$ and the seasonal migration of residents and those from outside the region for agricultural work has made mobility an important aspect of life. For FSWs, the Tan-Zam highway is a source of clients ${ }^{39}$ and plays a role in their mobility within and outside of the region. Within this context, the objective of this study was to examine associations between work-related mobility and GBV among FSWs in Iringa.

\section{METHODS}

\section{Sampling}

This cross-sectional analysis was conducted on baseline data gathered as part of Project Shikamana (Kiswahili for 'Stick together'), a rights-based community empowerment-based combination HIV prevention intervention. ${ }^{37}$ For the phase II community-randomised trial of this intervention, a baseline survey was administered between October 2015 and April 2016. FSWs were recruited in intervention and control communities for participation in the study using venue-based time-location sampling. Entertainment venues where sex work commonly occurs were used as locations for sampling. Times and venues where FSWs could be found were identified and used to construct a sampling frame of time and location units. Units were randomly sampled, and FSWs were systematically selected for recruitment in each unit. ${ }^{37}$ FSWs were recruited until 100 FSWs who were HIV positive were enrolled in each study community. Estimates of the study's power to estimate differences in proportion virally suppressed and relative risks of HIV are described in greater detail elsewhere. ${ }^{37}$ Tanzanian interviewers from the Muhimbili University of Health and Applied Sciences were trained by study staff and administered surveys using tablets. Surveys were conducted in private locations at or near venues or local drop-in centres to ensure participants' privacy and confidentiality. FSWs were eligible for participation if they were 18 years or older and had exchanged sex for money within the past month. ${ }^{37}$ The enrolment rate was $65 \%$, with only $5 \%$ explicitly refusing participation among those eligible (24 of 762 FSWs). Informed consent was given by all study participants prior to data collection. As a result of the sensitive topics covered in the survey, a referral list was available to participants that included local social and health services (eg, GBV services), if needed.

\section{Gender-based violence, work-related mobility and sociodemographic characteristics}

The outcome of interest was recent experience (within the past 6 months) of physical or sexual violence. Experience of GBV was a dichotomous variable based on nine indicators adapted from WHO and work by Decker et $a l$ that assessed exposure to GBV from either partners or non-partners. ${ }^{837}{ }^{40}$ FSWs reporting any recent GBV were compared with those with no recent GBV. Severity of GBV was measured by disaggregating two less severe forms (slapped/had something thrown at them or pushed/shoved) from seven more severe forms (hit with 
fist, kicked/dragged/beaten, choked/burnt, threatened with a violent, hurt with a violent weapon, raped or gang raped). ${ }^{40}$

The explanatory variable of interest was work-related mobility. FSWs were defined as mobile for work if they had, in the past 6 months, exchanged sex for money in another district within the Iringa region or outside of the Iringa region. This categorical variable compared FSWs who were both intraregionally and inter-regionally mobile to those who were (1) either intraregionally or inter-regionally mobile but not both and (2) not recently mobile. This categorisation compared levels of work-related mobility and was based on exploratory analyses suggesting similar associations between intraregional and inter-regional work-related mobility and the outcome of interest.

Sociodemographic characteristics included recent general mobility outside of the Iringa region, age, marital status, education, monthly income, study community, alcohol consumption and HIV status. Recent general mobility was defined as any travel outside of Iringa, not specifically work-related, within the past 6 months. Age was a continuous variable ranging from 18 to 55 years. Education was dichotomised and compared those who received some secondary schooling or more with those with either primary or no schooling. Monthly income was dichotomised at the median such that those earning $120000 \mathrm{Tsh}$ ( US\$54) or more were compared with those earning $<120000$ Tsh per month. Participants were from one of two communities: Ilula, the intervention community, or Mafinga, the control community. Alcohol consumption was measured using 10 questions from the WHO's Alcohol Use Disorders Identification Test assessment that assessed alcohol consumption and dependence. ${ }^{41}$ Responses to each question ranged from zero to four, with four indicating greater consumption or more harmful practices. Hazardous/harmful drinking was determined based on a summary score of each FSW's responses to these 10 questions, with scores of 8 or higher categorised as hazardous/ harmful consumption. ${ }^{41}$ Current HIV status was assessed at enrolment using a rapid HIV test to minimise potential self-report bias. ${ }^{37}$

Sex work-related characteristics of interest were sex work venue type, average number of clients per week, mobility-related place where FSWs meet or have sex with clients, time in sex work, percentage of income from sex work and internalised sex work-related stigma. Venue type was categorical based on the type of establishment in which women currently worked (single response): modern bars, traditional bars, guesthouses, independent venues or restaurants/hotels/other. Average number of clients per week was based on FSW recall and dichotomised ( $>2$ clients vs $\leq 2$ clients). Mobility-related place where FSWs meet or have sex with clients was based on whether FSWs reported meeting clients at truck stops or having sex with clients in a private vehicle. Length of time in sex work was dichotomous comparing those in sex work for 5 or more years with those in sex work for
$<5$ years. Percentage of total income from sex work was dichotomised at $50 \%$ ( $>50 \%$ vs $\leq 50 \%$ ). Internalised sex work-related stigma, which refers to FSWs' acceptance of the negative attitudes society holds about them, ${ }^{42}$ was assessed based on responses to 13 indicators (Likert scale) measuring internalised stigma related to engagement in sex work. This scale was validated among FSWs in the Dominican Republic. ${ }^{43}$ Exploratory factor analysis was performed on these 13 indicators, suggesting that all indicators loaded highly on a single factor with high reliability $(\alpha=0.86)$. Scale scores ranged from 1 to 40 , with higher scores signifying greater sex work-related stigma.

\section{Data analysis}

Descriptive statistics were used to examine distributions of all relevant indicators. $\chi^{2}$ or Fisher's exact tests, t-test or analysis of variance assessed preliminary bivariate associations. Bivariate and multivariate binary and multinomial logistic regression models were fit for each GBV outcome variable. To adjust for the potential intraclass correlations between individuals recruited from the same venues, generalised estimating equations and generalised linear latent and mixed models with robust variance estimation were used for binary logistic and multinomial logistic regression models, respectively. Variance inflation factors (VIFs) of included covariates were examined to determine if there was evidence of collinearity among covariates; VIFs were all close to one, suggesting lack of significant collinearity among covariates in final models. Multivariate models were finalised using (1) postestimation F-tests to assess relative contribution of covariates to the models and (2) comparisons of Akaike's Information Criteria across different models. Due to low missingness in final models $(7 \%)$, models presented here are based on complete case analyses. Hosmer-Lemeshow goodness-of-fit tests were used to determine model fit. All models were adjusted for their community of residence where they were recruited and were good fits of the data $(p>0.05)$. All analyses were performed in Stata V.15 (StataCorp, 2017).

\section{Participant involvement}

FSWs were consulted through extensive formative research conducted prior to the baseline survey. ${ }^{44}$ FSWs are also members of a community advisory board and are consulted on all aspects of this study. While participants were not specifically involved in the development of the research question or analyses presented here, dissemination meetings, including one meeting on experiences of violence, have been conducted to share findings from the baseline study with FSWs in Iringa.

\section{RESULTS}

\section{Description of the sample}

Among 496 participants in the survey, the mean age was 27 years (SD: 6.7 ; range: $18-55$ years). Half of participants earned $<12000$ Tsh $(\sim$ US\$54) per month. Sixty per cent 
of FSWs reported hazardous or harmful drinking, and $41 \%$ were HIV positive (table 1 ).

Forty per cent of FSWs reported experiencing either a physical or sexual form of GBV in the past 6 months. Thirty per cent of FSWs had experienced more severe GBV. Thirty-three per cent of FSWs reported work-related mobility to another district within the Iringa region or outside the Iringa region in the last 6 months. Twelve per cent of FSWs were both intraregionally and inter-regionally mobile for sex work in the last 6 months. Forty-three per cent of FSWs reported any travel (not necessarily work-related) outside of the Iringa region in the past 6 months (table 1). A higher percentage of FSWs reported working in modern bars (42\%) and guesthouses (28\%) than in traditional bars (19\%; table 2). Thirty-seven per cent of FSWs reported having more than two clients (range: 0-40 clients), on average, per week and 51\% had been sex workers for at least 5 years (table 2 ).

\section{Characteristics of mobile and non-mobile FSWs}

Intraregionally and inter-regionally mobile FSWs were younger on average (mean: 26 years, SD: 5.3) than non-mobile FSWs (mean: 28 years, SD: 7.2; $\mathrm{p}<0.05$ ). A higher percentage of intraregionally and inter-regionally mobile FSWs had monthly incomes of at least 120 000 Tsh ( $71 \%$ vs $45 \%$; $\mathrm{p}<0.01$; table 1 ). These mobile FSWs also reported more hazardous/harmful drinking practices than FSWs not mobile for work ( $75 \%$ vs $55 \%$; $\mathrm{p}<0.01$; table 1 ). Recent work-related mobility was positively associated with recent general mobility, with higher percentages of highly work-mobile FSWs reporting recent mobility outside of the Iringa region $(67 \%)$ as compared with less work-mobile FSWs ( $<<0.001$; table 1$)$. A larger percentage of intraregionally and inter-regionally mobile FSWs worked in modern bars $(48 \%)$ and guesthouses $(37 \%)$ than did non-mobile FSWs $(39 \%$ and $25 \%$, respectively; $\mathrm{p}<0.01$; table 2 ). These intraregionally and inter-regionally mobile FSWs also reported a higher average number of clients per week than FSWs not mobile for work ( $>2: 51 \%$ vs $32 \%$; $p<0.01$; table 2 ). While only $3 \%$ of FSWs reported meeting clients at truck stops and having sex in private vehicles, a higher percentage of FSWs who were intraregionally and inter-regionally mobile for work reported meeting and having sex with clients in these locations. However, these characteristics were not statistically significantly associated with recent GBV (table 2). There was no significant difference in FSWs' current HIV statuses based on their work-related mobility (table 1).

\section{Work-related mobility and gender-based violence}

A higher percentage of FSWs reporting recent GBV were both intraregionally or inter-regionally mobile for sex work as compared with those not reporting recent GBV $(17 \%$ vs $8 \%$; $\mathrm{p}<0.01$; table 1$)$. In final adjusted models, having recently exchanged sex for money intraregionally and inter-regionally was significantly associated with increased odds of experiencing GBV in the past 6 months (adjusted OR (AOR): 1.89 ; $95 \%$ CI: 1.06 to 3.38 ; $\mathrm{p}<0.05$; table 3 ).
There was no significant difference when comparing odds of recent GBV for those reporting only one type of work-related mobility with non-mobile FSWs. Any recent general mobility was associated with $60 \%$ increased odds of recent GBV (AOR: 1.60; 95\% CI: 1.07 to 2.39; $<<0.05$; table 3). FSWs who reported hazardous/harmful drinking practices had 1.9 times greater odds of reporting recent GBV as compared with those with less hazardous/harmful consumption (AOR: 1.93; 95\% CI: 1.25 to 2.97; $\mathrm{p}<0.01$; table 3). While having a higher average number of clients per week was significantly associated with increased odds of recent GBV in unadjusted models (OR: 1.91; 95\% CI: 1.33 to $2.75 ; \mathrm{p}<0.001$ ), this association was not significant in adjusted models (table 3 ). Women reporting higher levels of internalised sex work-related stigma were significantly more likely to report recent GBV as compared with those with less stigma (AOR: 1.05; 95\% CI: 1.02 to 1.08; $\mathrm{p}<0.01$; table 3 ).

In adjusted multinomial models disaggregating experiences of GBV by severity, those reporting both intraregional and inter-regional work-related mobility had a significantly higher relative risk ratios (RRR: 2.51) of more severe GBV relative to no GBV (95\% CI: 1.33 to 4.74; $\mathrm{p}<0.01)$ as compared with those not mobile for sex work (table 4). FSWs reporting recent general mobility, a higher average number of clients per week, higher sex work-related stigma and hazardous/harmful drinking practices similarly had significantly higher relative risks of more severe GBV relative to no GBV, as compared with their counterparts (table 4 ).

\section{DISCUSSION}

These analyses extend our knowledge about the role of mobility in sex workers' lives and health in Iringa, Tanzania. While previous research has examined the health risks of mobility on the Tan-Zam highway for migrant workers and truck drivers, ${ }^{39}$ no studies have situated Iringa and the Tan-Zam highway in discussions of FSW mobility and GBV. Moving beyond a singular focus on FSWs' HIV risk, we prioritised a holistic understanding of FSWs' daily lives and how aspects of their work, such as their work-related mobility, are linked with experiences of GBV. With $40 \%$ of participants reporting recent GBV, violence was a major concern for both mobile and non-mobile FSWs. Conversely, evidence from this study suggests that FSWs mobile for work had higher odds of recently experiencing GBV than did FSWs not mobile for work. Our findings highlight the unique contribution of work-related mobility to FSWs' odds of recent GBV and suggest that such differences in violence could be the result of work environments wherein violence from clients is more likely to occur. These findings support results from studies with FSWs in quite different settings ${ }^{23} 252730$ and begin to fill the gap identified in a recent systematic review by Deering et al on violence experienced by FSWs around the world. ${ }^{2}$ 


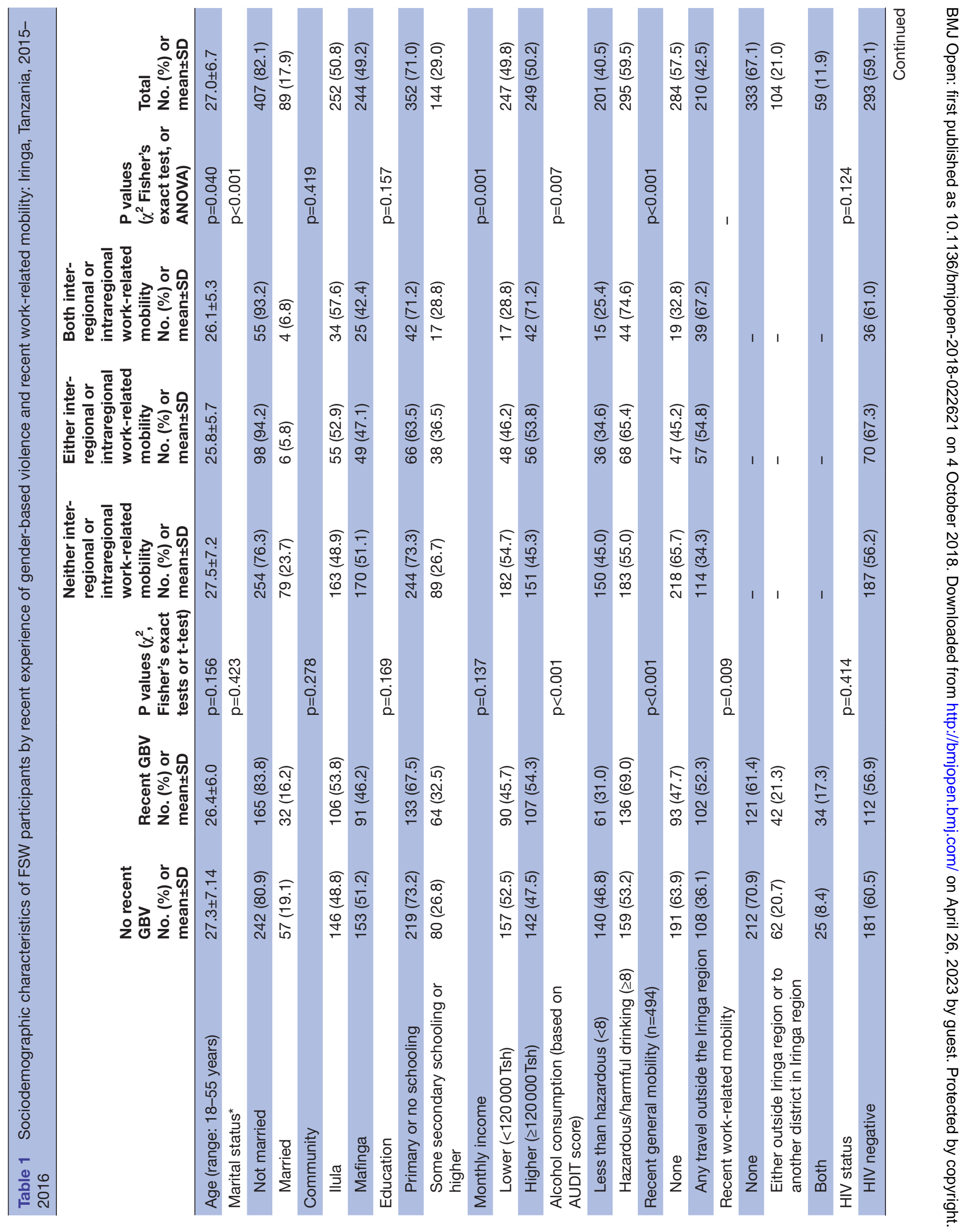




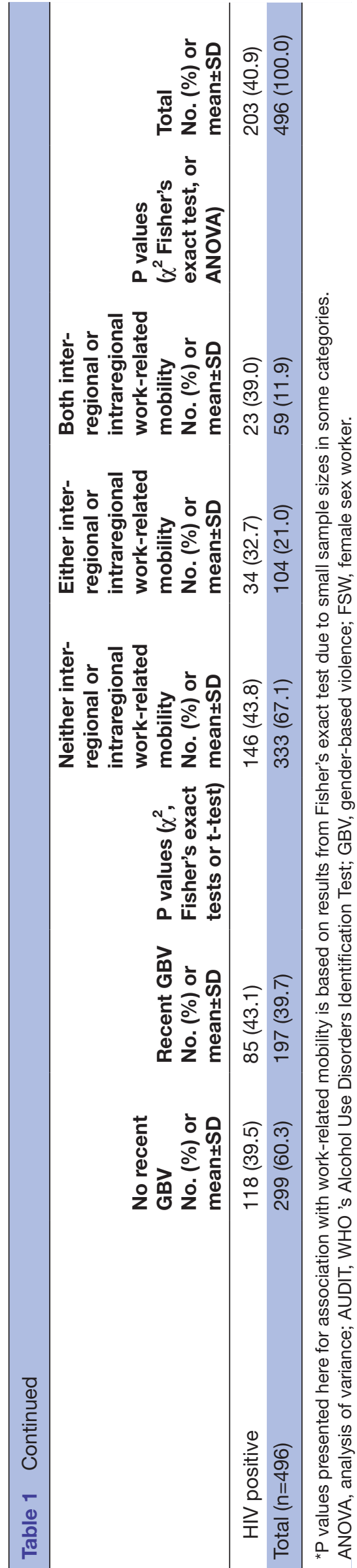

In light of the negative health effects of experiencing GBV and the implications GBV has for FSWs' human rights, sexual risk behaviours and HIV infections, these findings highlight the urgent need for programmes to work with mobile FSWs in the Iringa region. Extending previous research on the potential link between work-related mobility and GBV among FSWs, we also identified an association between mobility and GBV severity. FSWs who were highly mobile for work had higher relative risk of having recently experienced more severe GBV (as compared with no recent GBV) than those who were not mobile. More severe forms of violence included violent threats and sexual violence, which pose significant emotional, mental and physical health risks for FSWs. These findings should be used to support audience segmentation analyses to inform programmes working to reduce and prevent GBV as they identify those most vulnerable FSWs, such as those that are more mobile.

While some studies have argued that FSWs may be mobile or migrate in response to stigma or discrimination, ${ }^{2045}$ there was no significant difference in internalised sex work stigma comparing mobile and non-mobile FSWs in this sample. Internalised sex work stigma was positively associated with recent GBV as well as more severe forms of GBV, which supports findings from previous studies in sub-Saharan Africa and elsewhere emphasising how stigma and discrimination can be internalised and can negatively influence how people treat and interact with FSWs. ${ }^{20} 2327$

Alcohol consumption and number of clients may be two pathways through which work-related mobility affects exposure to GBV. A larger percentage of mobile FSWs than non-mobile FSWs reported hazardous or harmful drinking practices, and such practices were positively associated with recent GBV in adjusted models. These findings contrast those from India, where mobility was not significantly associated with alcohol consumption among FSWs. ${ }^{28}$ Work-related mobility was also shown to be positively associated with average number of clients per week. FSWs that are more mobile may have more clients, which may increase their risk for more severe forms of GBV. In this study, having a higher number of clients per week had a positive relationship with recent GBV, but only comparing relative risk of more severe violence relative to no violence. Further analyses of the associations between mobility, alcohol consumption and number of clients, and their implications for GBV, are necessary.

Some researchers have identified an interaction effect between mobility and GBV that increases FSWs' risk for HIV and other poor mental health outcomes. ${ }^{14}{ }^{23}$ Future longitudinal studies should draw on the associations presented here to identify how FSWs' work environments impact their future health and well-being. Such longitudinal research would enable an investigation of the temporal relationship between work-related mobility and GBV.

As findings presented in this article were based on cross-sectional associations, we were unable to specify 


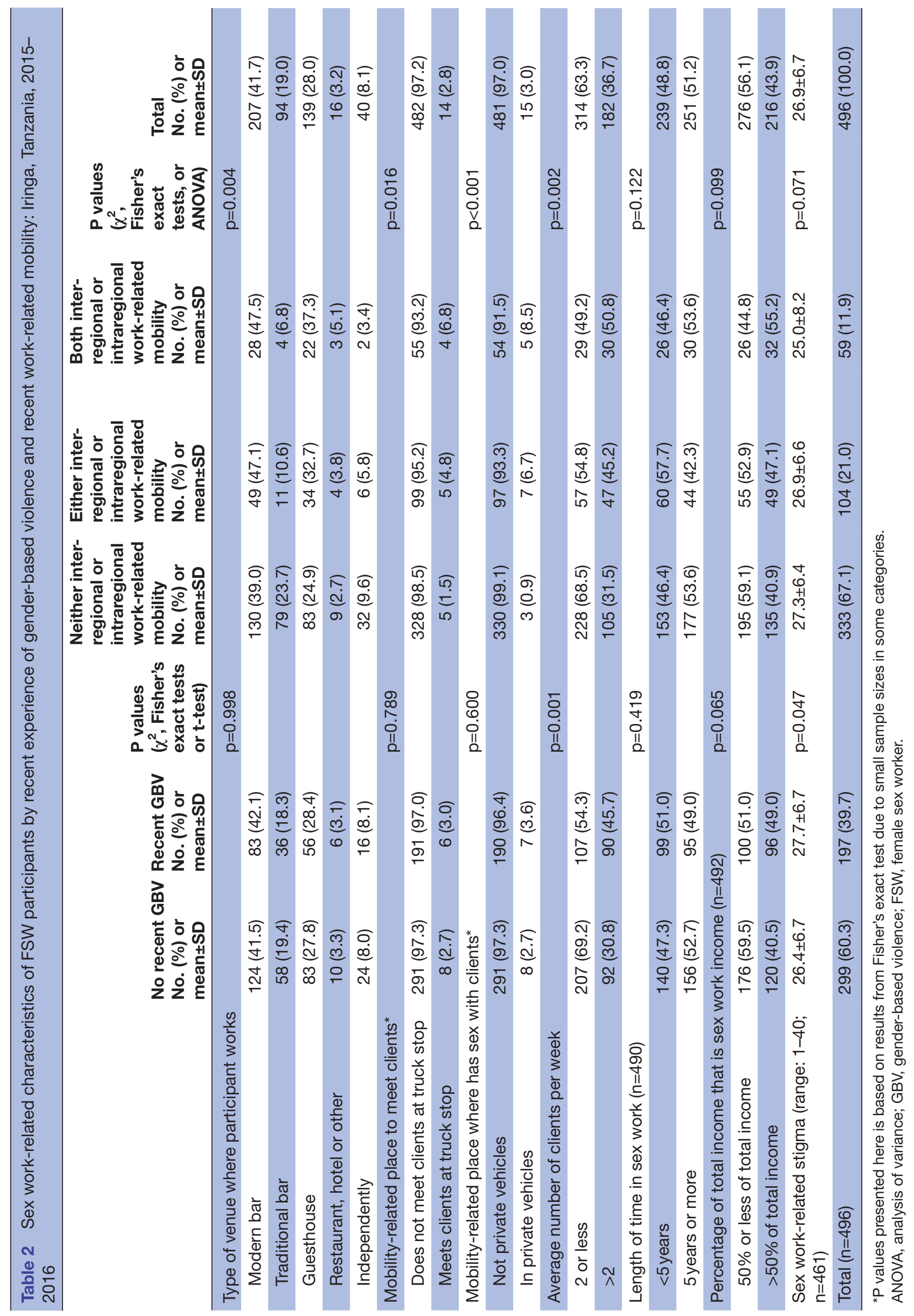


Table 3 Unadjusted and adjusted OR of recent experience of any GBV by recent FSW work-related mobility, general mobility and relevant sociodemographic characteristics and sex work-related characteristics: Iringa, Tanzania, 2015-2016

\begin{tabular}{|c|c|c|}
\hline & Unadjusted & Adjusted† \\
\hline Variables & OR $(95 \% \mathrm{Cl})$ & OR† (95\% Cl) \\
\hline \multicolumn{3}{|l|}{ Recent work-related mobility (ref: neither) } \\
\hline Either & 1.16 (0.79 to 1.72$)$ & $0.91(0.60$ to 1.36$)$ \\
\hline Both & $2.35^{\star *}(1.34$ to 4.09$)$ & $1.89^{*}(1.06$ to 3.38$)$ \\
\hline \multicolumn{3}{|l|}{ Recent general mobility } \\
\hline Any travel outside the Iringa region vs none (ref) & $1.93^{\star \star \star}(1.33$ to 2.80$)$ & $1.60^{*}(1.07$ to 2.39$)$ \\
\hline Age (continuous) & 0.98 (0.95 to 1.00$)$ & 0.97 (0.94 to 1.00$)$ \\
\hline \multicolumn{3}{|l|}{ Monthly income } \\
\hline Higher ( $\geq 120000$ Tsh) vs lower (<120000 Tsh) (ref) & 1.32 (0.96 to 1.81$)$ & $1.19(0.83$ to 1.68$)$ \\
\hline \multicolumn{3}{|l|}{ Average number of clients per week } \\
\hline$>2$ vs $\leq 2$ (ref) & $1.91^{\star \star \star}(1.33$ to 2.75$)$ & $1.31(0.87$ to 1.98$)$ \\
\hline Sex work-related stigma (continuous) & $1.03^{* *}(1.00$ to 1.06$)$ & $1.05^{\star *}(1.02$ to 1.08$)$ \\
\hline \multicolumn{3}{|l|}{ Alcohol consumption } \\
\hline Hazardous/harmful consumption vs less than hazardous (ref) & $1.96^{* * *}(1.38$ to 2.77$)$ & $1.93^{* *}(1.25$ to 2.97$)$ \\
\hline \multicolumn{3}{|l|}{ HIV status } \\
\hline HIV positive vs HIV negative (ref) & $1.15(0.82$ to 1.61$)$ & $1.37(0.92$ to 2.04$)$ \\
\hline
\end{tabular}

OR from unadjusted and adjusted binary logistic regressions.

Robust Cls in parentheses.

Model also adjusted for community (Mafinga vs Ilula; $p>0.05$ ).

${ }^{*} \mathrm{P}<0.05,{ }^{* *} \mathrm{p}<0.01,{ }^{* * *} \mathrm{p}<0.001$.

$\dagger \mathrm{t}=460$ for adjusted model.

GBV, gender-based violence; FSW, female sex worker.

the temporal relationship between mobility and GBV. Mobility, for example, could have been the result, rather than a predictor, of violence. ${ }^{45}$ Furthermore, the outcome and explanatory variables of interest were self-reported, which may be affected by recall bias. Additionally, by including women in this study who had exchanged sex for money in the past month, some FSWs had recently started engaging in sex work and may have had lower work-related mobility than FSWs who had worked for at least 6 months in sex work. As a result, work-related mobility measures may be lower than could be expected if all FSWs had been exchanging sex for money for at least 6 months, which may underestimate associations described here.

Future qualitative research to explore this sensitive topic with mobile FSWs-including what motivates or leads them to be mobile-would facilitate an in-depth understanding of FSWs' work environments before, during and after mobility. Our finding that a higher percentage of FSWs who were both intraregionally and inter-regionally mobile for work-reported meeting clients in trucks or having sex in private vehicles provides some evidence in support of the connection between mobility and FSWs' risky work environments. Future exploration of the context in which mobile FSWs work and their experiences of violence, including where violence takes place and perpetrator type and more nuanced information about type of violence experienced, could strengthen our understanding of the associations presented here.
As participants in a community-randomised trial, participants whose responses were analysed here are not necessarily representative of all FSWs in Tanzania. However, this is a hard to reach population where typical probability sampling approaches are challenging. Venue-based time-location sampling was used to address the challenges of recruiting a population-based sample of FSWs. This sampling approach enables statistical methods to be used to adjust for correlations within communities where FSWs were recruited.

\section{PUBLIC HEALTH IMPLICATIONS}

In light of the health effects of GBV on FSWs' emotional, mental and physical health, associations between aspects of FSWs' work, such as mobility, and GBV suggest that work-related mobility may be an important factor for public health programmes to consider when working with FSWs. Mobile FSWs may have different risks as a result of their mobility ${ }^{20} 45$ and therefore may have different needs for GBV services and services that facilitate preventive health behaviours, reduce risky behaviours, and encourage care-seeking. To address FSWs' needs, interventions like Project Shikamana must be locally informed and include messaging that is relevant to FSWs who are mobile for work. Such messaging could seek to increase awareness of GBV, GBV prevention approaches and available GBV services in communities and regions 
Table 4 Unadjusted and adjusted RRR of recent experience of GBV (by severity) by FSW work-related mobility, general mobility and relevant sociodemographic characteristics and sex work-related characteristics: Iringa, Tanzania, 2015-2016

\begin{tabular}{|c|c|c|c|c|}
\hline & Unadjusted RRR & Unadjusted RRR & Adjusted RRR & Adjusted RRR \\
\hline Variables & $\begin{array}{l}\text { Less severe GBV vs } \\
\text { no GBV } \\
\text { RRR }(95 \% \mathrm{Cl})\end{array}$ & $\begin{array}{l}\text { More severe GBV vs } \\
\text { no GBV } \\
\text { RRR }(95 \% \mathrm{Cl})\end{array}$ & $\begin{array}{l}\text { Less severe GBV vs } \\
\text { no GBV† } \\
\text { RRR }(95 \% \text { Cl) }\end{array}$ & $\begin{array}{l}\text { More severe GBV vs } \\
\text { no GBV† } \\
\text { RRR }(95 \% \text { Cl) }\end{array}$ \\
\hline \multicolumn{5}{|l|}{$\begin{array}{l}\text { Recent work-related mobility (ref: } \\
\text { neither) }\end{array}$} \\
\hline Either & $0.81(0.37$ to 1.76$)$ & 1.31 (0.85 to 2.01$)$ & $0.70(0.32$ to 1.54$)$ & $0.98(0.64$ to 1.52$)$ \\
\hline \multicolumn{5}{|l|}{ Recent general mobility } \\
\hline $\begin{array}{l}\text { Any travel outside the Iringa } \\
\text { region vs none }\end{array}$ & $1.80(0.95$ to 3.41$)$ & $2.04^{\star \star}(1.32$ to 3.13$)$ & $1.66(0.86$ to 3.19$)$ & $1.59^{\star}(1.00$ to 2.53$)$ \\
\hline Age (continuous) & $0.95^{\star}(0.90$ to 0.99$)$ & 0.99 (0.96 to 1.02$)$ & $0.93^{\star *}(0.88$ to 0.98$)$ & $0.98(0.94$ to 1.02$)$ \\
\hline \multicolumn{5}{|l|}{ Monthly income } \\
\hline$>2$ vs $\leq 2$ (ref) & 1.03 (0.53 to 2.03) & $2.41^{\star \star \star}(1.63$ to 3.56$)$ & $0.73(0.35$ to 1.49$)$ & $1.61^{*}(1.04$ to 2.49$)$ \\
\hline $\begin{array}{l}\text { Sex work-related stigma } \\
\text { (continuous) }\end{array}$ & $1.02(0.97$ to 1.06$)$ & $1.04^{*}(1.00$ to 1.08$)$ & 1.04 (0.99 to 1.08$)$ & $1.06^{\star \star}(1.02$ to 1.10$)$ \\
\hline \multicolumn{5}{|l|}{ Alcohol consumption } \\
\hline $\begin{array}{l}\text { Hazardous/harmful consumption } \\
\text { vs less than hazardous (ref) }\end{array}$ & 1.30 (0.75 to 2.26$)$ & $2.34^{\star \star \star}(1.54$ to 3.56$)$ & 1.54 (0.84 to 2.84$)$ & $2.17^{\star \star}(1.33$ to 3.53$)$ \\
\hline \multicolumn{5}{|l|}{ HIV status } \\
\hline HIV positive vs HIV negative (ref) & $1.04(0.59$ to 1.86$)$ & 1.19 (0.82 to 1.72$)$ & 1.37 (0.78 to 2.40$)$ & 1.39 (0.90 to 2.15$)$ \\
\hline Level 2 (cluster) variance (StE) & - & - & $0.15(0.21)$ & \\
\hline
\end{tabular}

RRRs from unadjusted and adjusted multinomial logistic regressions.

Robust Cls in parentheses.

Model also adjusted for community (Mafinga vs llula; $p<0.05$ in adjusted models for less severe GBV vs no GBV only).

${ }^{*} \mathrm{P}<0.05,{ }^{* *} \mathrm{p}<0.01,{ }^{* * *} \mathrm{p}<0.001$.

$\dagger \mathrm{n}=460$ for adjusted model.

GBV, gender-based violence; FSW, female sex worker; RRR, relative risk ratio.

where mobile FSWs travel for work. Mobility may disrupt access to services or programmes, and programmes must take this into account when developing their activities. Different stages of mobility-such as origin, transit, destination and return, may also require unique programmatic approaches. ${ }^{45}$ Research with migrants has shown that the health risks faced by mobile populations differ at predeparture, during transit, at the destination and during the return. ${ }^{46}$ Programmes must develop content and activities that are accessible to those at each stage of mobility. As we formulate programmes, it will be imperative that we keep in mind other potential disruptive effects of mobility on FSWs' daily lives. Community empowerment responses to HIV, which enable FSWs to work within existing environments characterised by restrictive laws, stigma and discrimination, may require innovative strategies to address how to continue to engage and support mobile FSWs when they travel-either for work or for other reasons-as such mobility may impact their participation in an intervention or the effects of the intervention at the community level.

\section{CONCLUSION}

This study examined the association between FSWs' work-related mobility within and outside of the Iringa region and its association with recent GBV. Positive associations between work-related mobility and any recent GBV as well as more severe GBV even after adjusting for general mobility extended existing knowledge of mobile FSWs' lives and risks in Iringa and highlighted how FSWs' work environments are implicated in their health. Programmes working to address the social and structural factors that affect FSWs' health and well-being must incorporate mobility into their understanding of vulnerability and FSWs' access to services.

\section{Author affiliations}

${ }^{1}$ Department of Health, Behavior and Society, Johns Hopkins Bloomberg School of Public Health, Baltimore, Maryland, USA

${ }^{2}$ Division of Prevention Science, University of California San Francisco, San Francisco, California, USA

${ }^{3}$ Division of HIV, ID, and Global Medicine, University of California, San Francisco, California, USA 
${ }^{4}$ Department of Epidemiology, Johns Hopkins Bloomberg School of Public Health, Baltimore, Maryland, USA

${ }^{5}$ Department of Statistics, University of Haifa, Mt Carmel, Israel

${ }^{6}$ Muhimbili University of Health and Allied Sciences, Dar es Salaam, Tanzania

${ }^{7}$ Department of Sociology, American University, Washington, DC, USA

Acknowledgements The authors would like to thank the study participants, the community and study advisory boards of Project Shikamana, MUHAS staff, peer navigators, HIV providers and all others who have assisted with Project Shikamana.

Contributors ZMH and DLK conceptualised the research question. ZMH conducted analyses and led manuscript writing. AML and NG provided input on study design and analyses and contributed to the revisions of the manuscript. JKM assisted with the study design and contributed to the revisions of the manuscript. SL assisted with the study design and contributed to the revisions of the manuscript. DLK supervised the study, provided input on study design and analyses and contributed to the revisions of the manuscript.

Funding This study was funded by the US National Institute of Mental Health through R01MH104044. It was facilitated by the infrastructure and resources of the Johns Hopkins University Center for AIDS Research, a US NIH-funded programme (1P30AI094189). It was also supported by the following NIH Institutes and Centers: NIAID, NCI, NICHD, NHLBI, NIDA, NIMH, NIA, FIC, NIGMS, NIDDK and OAR.

Disclaimer The content presented here is solely the responsibility of the authors and does not necessarily represent the official views of the NIH. NIH was not involved in the design of this study, analysis or interpretation of data, manuscript writing or decision to submit for publication the results presented here.

Competing interests None declared.

Patient consent Not required.

Ethics approval This study was approved by the Johns Hopkins Bloomberg School of Public Health institutional review board (IRB) in Baltimore and IRBs at the Muhimbili University of Health and Applied Sciences and the National Institute of Medical Research in Tanzania.

Provenance and peer review Not commissioned; externally peer reviewed.

Data sharing statement Data set is not publicly available. Contact the corresponding author for further details about the statistical code and/or data set.

Open access This is an open access article distributed in accordance with the Creative Commons Attribution Non Commercial (CC BY-NC 4.0) license, which permits others to distribute, remix, adapt, build upon this work non-commercially, and license their derivative works on different terms, provided the original work is properly cited, appropriate credit is given, any changes made indicated, and the use is non-commercial. See: http://creativecommons.org/licenses/by-nc/4.0/.

\section{REFERENCES}

1. Shannon K, Goldenberg SM, Deering KN, et al. HIV infection among female sex workers in concentrated and high prevalence epidemics: why a structural determinants framework is needed. Curr Opin HIV AIDS 2014;9:174-82

2. Deering KN, Amin A, Shoveller J, et al. A systematic review of the correlates of violence against sex workers. Am J Public Health 2014;104:e42-54.

3. Nations U. Declaration on the elimination of violence against women. New York: United Nations General Assembly, 1993.

4. Devries KM, Mak JY, García-Moreno C, et al. Global health. The global prevalence of intimate partner violence against women. Science 2013;340:1527-8.

5. Campbell J, Jones AS, Dienemann J, et al. Intimate partner violence and physical health consequences. Arch Intern Med 2002;162:1157-63.

6. Pando MA, Coloccini RS, Reynaga E, et al. Violence as a barrier for HIV prevention among female sex workers in Argentina. PLoS One 2013;8:e54147.

7. Shannon $\mathrm{K}$, Csete J. Violence, condom negotiation, and HIV/STI risk among sex workers. JAMA 2010;304:573-4.

8. Decker MR, McCauley HL, Phuengsamran D, et al. Violence victimisation, sexual risk and sexually transmitted infection symptoms among female sex workers in Thailand. Sex Transm Infect 2010;86:236-40.

9. Decker MR, Wirtz AL, Baral SD, et al. Injection drug use, sexual risk, violence and STI/HIV among Moscow female sex workers. Sex Transm Infect 2012;88:278-83.
10. Decker MR, Wirtz AL, Pretorius C, et al. Estimating the impact of reducing violence against female sex workers on HIV epidemics in Kenya and Ukraine: a policy modeling exercise. Am J Reprod Immunol 2013;69(Suppl 1):122-32.

11. Beattie TS, Bhattacharjee $P$, Ramesh BM, et al. Violence against female sex workers in Karnataka state, south India: impact on health, and reductions in violence following an intervention program. $B M C$ Public Health 2010;10:476.

12. Shannon K, Strathdee SA, Goldenberg SM, et al. Global epidemiology of HIV among female sex workers: influence of structural determinants. Lancet 2015;385:55-71.

13. Patel SK, Saggurti N, Pachauri S, et al. Correlates of mental depression among female sex workers in Southern India. Asia Pac J Public Health 2015;27:809-19.

14. Patel SK, Ganju D, Prabhakar P, et al. Relationship between mobility, violence and major depression among female sex workers: a crosssectional study in southern India. BMJ Open 2016;6:e011439.

15. Beattie TS, Bhattacharjee $P$, Isac $S$, et al. Declines in violence and police arrest among female sex workers in Karnataka state, south India, following a comprehensive HIV prevention programme. J Int AIDS Soc 2015;18:20079.

16. Beyrer C, Crago AL, Bekker LG, et al. An action agenda for HIV and sex workers. Lancet 2015;385:287-301.

17. Decker MR, Lyons C, Billong SC, et al. Gender-based violence against female sex workers in Cameroon: prevalence and associations with sexual HIV risk and access to health services and justice. Sex Transm Infect 2016;92:599-604.

18. Decker MR, Crago AL, Chu SK, et al. Human rights violations against sex workers: burden and effect on HIV. Lancet 2015;385:186-99.

19. Kerrigan D, Wirtz A, Baral S, et al. The global HIV epidemics among sex workers. Washington, D.C: World Bank, 2013.

20. Scorgie F, Chersich MF, Ntaganira I, et al. Socio-demographic characteristics and behavioral risk factors of female sex workers in sub-saharan Africa: a systematic review. AIDS Behav 2012;16:920-33.

21. van Blerk L. AIDS, mobility and commercial sex in Ethiopia: implications for policy. Contested bodies of childhood and youth Berlin: Springer, 2010:232-46.

22. Rushing R, Watts $C$, Rushing $S$. Living the reality of forced sex work: perspectives from young migrant women sex workers in northern Vietnam. J Midwifery Womens Health 2005;50:e41-4.

23. Ramesh S, Ganju D, Mahapatra B, et al. Relationship between mobility, violence and HIV/STI among female sex workers in Andhra Pradesh, India. BMC Public Health 2012;12:764.

24. Wang H, Chen RY, Sharp GB, et al. Mobility, risk behavior and HIV/STI rates among female sex workers in Kaiyuan City, Yunnan Province, China. BMC Infect Dis 2010;10:198.

25. Goldenberg SM, Chettiar J, Nguyen P, et al. Complexities of shortterm mobility for sex work and migration among sex workers: violence and sexual risks, barriers to care, and enhanced social and economic opportunities. J Urban Health 2014;91:736-51.

26. Pitpitan EV, Kalichman SC, Eaton LA, et al. HIV/STI risk among venue-based female sex workers across the globe: a look back and the way forward. Curr HIVIAIDS Rep 2013;10:65-78.

27. Saggurti N, Jain AK, Sebastian MP, et al. Indicators of mobility, socio-economic vulnerabilities and HIV risk behaviours among mobile female sex workers in India. AIDS Behav 2012;16:952-9.

28. Verma RK, Saggurti N, Singh AK, et al. Alcohol and sexual risk behavior among migrant female sex workers and male workers in districts with high in-migration from four high HIV prevalence states in India. AIDS Behav 2010;14(Suppl 1):31-9.

29. Wong WC, Holroyd E, Chan EY, et al. "One country, two systems": Sociopolitical implications for female migrant sex workers in Hong Kong. BMC Int Health Hum Rights 2008;8:13.

30. Reed E, Gupta J, Biradavolu M, et al. Migration/mobility and risk factors for HIV among female sex workers in Andhra Pradesh, India: implications for HIV prevention. Int J STD AIDS 2012;23:e7-13.

31. Swain SN, Saggurti N, Battala M, et al. Experience of violence and adverse reproductive health outcomes, HIV risks among mobile female sex workers in India. BMC Public Health 2011;11:357.

32. Goldenberg SM, Brouwer KC, Jimenez TR, et al. Enhancing the ethical conduct of HIV research with migrant sex workers: human rights, policy, and social contextual influences. PLoS One 2016;11:e0155048.

33. Tanzania National AIDS Control Program, PSI Tanzania. HIV biological and behavioral surveys: Tanzania 2013. Female sex workers in seven regions: Dar es Salaam, Iringa, Mbeya, Mwanza, Tabora, Shinyanga and Mara: United Republic of Tanzania, Ministry of Health and Social Welfare, National AIDS Control Programme, 2013. 
34. Scorgie F, Nakato D, Harper E, et al. 'We are despised in the hospitals': sex workers' experiences of accessing health care in four African countries. Cult Health Sex 2013;15:450-65.

35. Okal J, Chersich MF, Tsui S, et al. Sexual and physical violence against female sex workers in Kenya: a qualitative enquiry. AIDS Care 2011;23:612-8

36. Mpondo BCT, Gunda DW, Kilonzo SB. HIV epidemic in Tanzania: the possible role of the key populations. AIDS Res Treat 2017;2017:1-7.

37. Kerrigan D, Mbwambo J, Likindikoki S, et al. Project Shikamana: baseline findings from a community empowerment-based combination HIV prevention trial among female sex workers in Iringa, Tanzania. J Acquir Immune Defic Syndr 2017;74(Suppl 1):S60.

38. Ghoshal N. "Treat us like human beings": discrimination against sex workers, sexual and gender minorities, and people who use drugs in Tanzania. New York, NY: Human Rights Watch, 2013.

39. Kohli A, Kerrigan D, Brahmbhatt $\mathrm{H}$, et al. Social and structural factors related to HIV risk among truck drivers passing through the Iringa region of Tanzania. AIDS Care 2017;29:957-60.

40. World Health Organization. WHO multi-country study on women's health and domestic violence against women: summary report of initial results on prevalence, health outcomes and women's responses. Geneva, Switzerland: WHO, 2005.

41. Babor TF, Higgins-Biddle JC, Saunders JB, et al. AUDIT: The alcohol use disorders identification test: Guidelines for use in primary health care, 2001.

42. Goffman E. Stigma: notes on the management of spoiled identity Englewood Cliffs, NJ: Prentice Hall, 1963.

43. Zulliger R, Maulsby C, Barrington C, et al. Retention in HIV care among female sex workers in the Dominican Republic: implications for research, policy and programming. AIDS Behav 2015;19:715-22.

44. Beckham S, Kennedy C, Brahmbhatt $\mathrm{H}$, et al. Strategic Assessment to Define a Comprehensive Response to HIV in Iringa, Tanzania. Research Brief: Female Sex Workers. Baltimore, MD: USAID Project Search and Research to Prevention (R2P), 2013.

45. Rocha-Jiménez T, Brouwer KC, Silverman JG, et al. Migration, violence, and safety among migrant sex workers: a qualitative study in two Guatemalan communities. Cult Health Sex 2016;18:965-79.

46. Zimmerman C, Kiss L, Hossain M. Migration and health: a framework for 21st century policy-making. PLoS Med 2011;8:e1001034. 